\title{
Suppression of Rhizoctonia solani Damping-off in Soybean (Glycine max L.) by Plant Growth Promoting Rhizobacteria Strains
}

\author{
Alaa El-Dein Omara ${ }^{1 *}$, Mohamed Nour El-Din ${ }^{1}$, Fathi Hauka ${ }^{2}$, Aida Hafez ${ }^{2}$, Sahar \\ El-Nahrawy ${ }^{1}$, Azza Ghazi ${ }^{1}$, Tamer Elsakhawy ${ }^{1}$ and Vincenzina Fusco ${ }^{3}$ \\ ${ }^{1}$ Agricultural Microbiology Department, Soil, Water and Environment Research \\ Institute, Agricultural Research Center, ${ }^{2}$ Microbiology Department, Faculty of \\ Agriculture, Mansoura University, Egypt. ${ }^{3}$ National Research Council of Italy, Institute \\ of Sciences of Food Production (ISPA-CNR), Bari, Italy.
}

\begin{abstract}
A STUDY was evaluated individual and combination strains of Plant Growth Promoting Rhizobacteria (PGPR) for its antagonist activity and suppression of Rhizoctonia solani AG2-3 causal agent of damping-off disease in soybean plant. Strains of Bradyrhizobium japonicum 110, Bacillus megaterium var. phosphaticum B6, Methylobacterium aminovorans ML3, M. rhodinum ML12, and Trichoderma viride 1433 species were used in the present study. In vitro, all tested strains showed a notable ability to inhibit mycelial growth of $R$. solani on different growth media. While, T.viride and M. rhodinum showed the highest rate of antagonism against $R$. solani. In vivo, in generally, PGPR treatments notably decreased damping-off and increased healthy plants, as compared to the control (infested soil). As compared to the uninoculated NPK fertilized control, higher growth parameters for shoot and root dry weight ( $\mathrm{g}$ plant $\left.^{-1}\right)$, number of nodules and dry weight of nodules $\left(\mathrm{mg} \mathrm{plant}^{-1}\right)$, chlorophyll content and NPK $\%$ of shoot and root, were recorded for the $\mathrm{T}_{11}$ (inoculation with B. japonicum $110+M$. aminovorans $\mathrm{ML} 3+$ B. megaterium var. phosphaticum $\mathrm{B} 6+T$. viride) and $\mathrm{T}_{12}$ (inoculation with B. japonicum $110+$ M. rhodinum ML12 + B. megaterium var. phosphaticum $\mathrm{B} 6+$ T. viride) treatments. Seeds yield of soybean plants attained higher values with all tested treatments. The obtained results of PGPR bacterial effects on damping-off disease and growth parameters of soybean recommend their use as an alternative tool rather than chemical fungicides. Such biocontrol approach should be included in the integrated management programs.
\end{abstract}

Keywords: Soybean; PGPR; Bacteria; Fungi; Damping-off

\section{Introduction}

Soybean (Glycine $\max$ L.) has recognized worldwide as an important source of protein (40$45 \%$ ), which cheaper than the animal sources of protein such as meat, fish, milk, egg etc. (Kaul and Das, 1986). In the soil ecosystem, pathogenic and non-pathogenic microorganisms are in competition with each other (Sikora and Reimann, 2004). All soil has an antagonistic potential against specific pathogens to prevent or reduce the spread of a pathogen, parasite or deleterious agents (Sikora, 1992). Seedling damping - off and root rot diseases of soybean are considered as limiting factors affecting plant growth and yield (Omar, 1986). Economically, damping-off disease is one of the most important diseases all over the world. The disease complex is caused by different pathogens such as Pythium, Phytophthora, Rhizoctonia and Fusarium. These pathogens are difficult to control for their persistence in the soil and wide host range. On the other hand, it is better to use some chemicals in controlling these diseases but, it considers expensive and not environmental friendly. So, many researchers have used bacterial biological control as a means of protection against soil-borne diseases (Elad et al. 1986, Ashour and Afify, 2000). However, more attention has been given to Plant Growth Promoting Rhizobacteria (PGPR), as the most important alternative to chemicals to help eco-friendly biological control of soil-borne pathogens (Arora et al. 2001).

The potential of PGPR to protect plant roots from soil-borne pathogens was demonstrated in several research works (Attia et al. 2011, Huang et

"Corresponding author e-mail: alaa.omara@yahoo.com

DOI: $10.21608 /$ jenvbs.2018.3231.1024

C2017 National Information and Documentation Center (NIDOC) 
al.2015, Keshavarz-Tohid et al.2017, Sadeghi etal. 2017, Lu et al. 2017). They found that inoculation of soybean with Bradyrhizobium japonicum, Bacillus cereus and Trichoderma viride strains significantly reduced damping-off and root rot diseases caused by $R$. solani and also enhanced nodulation status in the roots as well as increasing plant growth. There are several hypotheses about the mechanisms by which rhizobacteria improve growth dynamics such as production of the auxine indole acetic acid (Patten and Glick, 2002), and increased availability of nutrients in the rhizosphere by means of solubilization of unavailable forms of nutrients and/or production of metabolites such as siderophores, antibiotics, lytic enzyme, hydrogen cyanide that decrease the growth of phytopathogens and other deleterious microorganisms or through competition for nutrient and space can significantly improve plant health and promote growth by increasing of seedling emergence and yield (Glick, 1995). Therefore, the objectives of the present study are to evaluate some strains of PGPR singly or in combination for growth promotion of soybean plants and their ability to control soybean damping-off under laboratory and greenhouse conditions.

\section{Materials and methods}

\section{Microbial strains and growth conditions}

Bradyrhizobium japonicum strain 110, Bacillus megaterium var. phosphaticum (B6), from Bacteriology Laboratory, Sakha Agricultural Research Station, Agriculture Research Center, Egypt as a biofertilizer products were used in this study. Methylobacterium aminovorans (ML3) and Methylobacterium rhodinum (ML12) were obtained from Alaa El-Dein Omara, Researcher of Bacteriology Laboratory, Sakha Agricultural Research Station, Agriculture Research Center, Egypt. These strains were isolated in previous study as a PGPR from soil which data published in J. Agric. Sci. Mansoura University, 2(4), 2013. Pure cultures were routinely maintained on Yeast Extract Mannitol Agar (YEMA) (Vincent, 1970), Nutrient Agar (NA) (Atlas, 1997) and Ammonium Mineral Salt Agar (AMSA) (Wittenbury et al. 1970), respectively.

Trichoderma viride 1433 (Tv-1433) and Rhizoctonia solani AG2-3 provided by Department of Microbiology, Faculty of Agriculture, Mansoura University and Department of Plant Pathology, Agriculture Research Center, respectively, were also used in this study, Pure Env. Biodiv. Soil Security Vol.2 (2018) cultures of these strains were routinely maintained on Potato Dextrose Agar (PDA) medium (Okon et al. 1977) and all chemicals used are obtained from Merck-Co., Germany.

Seeds used

Seeds of soybean (Glycine max C.V. Giza 111), were kindly supplied by Department of Leguminous Crops, Sakha Agricultural Research Station, Egypt.

\section{Laboratory experiment (in vitro).}

The antagonistic activity against $R$. solani was evaluated by a dual culture technique (Sadfi et al. 2001). Briefly, each strain was streaked on to PDA, AMSA, NA, and YEMA media, respectively, in one side of the plate while disc $5 \mathrm{~mm}$ in diameter of $R$. solani strain was taken from 7 day-old culture and placed at the other side of the antagonist with triplicates. Plates were incubated at $30^{\circ} \mathrm{C}$ for one week. Reduction percent of $R$. solani after 5 days was calculated by the following formula of (Whipps, 1987).

Reduction \% $=\mathrm{R} 1-\mathrm{R} 2 / \mathrm{R} 1 \times 100$, where: R1 $=$ growth in control plates (without antagonism), and $\mathrm{R} 2$ = growth in the presence of the bioagent

\section{Pot experiment (in vivo):}

The pot experiment aimed to investigate the effect of inoculation with Bradyrhizobium japonicum St.110, Bacillus megaterium var. phosphaticum B6, Trichoderma viride, Methylobacterium aminovorans ML3 and Methylobacterium rhodinum ML12 either alone or in combination on soil infested and non-infested with the pathogen $R$. solani. Pot experiment was conducted in loam soil in texture having the following characteristics: $\mathrm{pH}, 7.91$; EC, $0.186 \mathrm{dS} \mathrm{m}^{-1}$; organic matter (\%), 1.12; particle size distribution sand, silt and clay (\%), 47.10, 35.60 and 17.30, respectively; soluble cations $\mathrm{Ca}^{+2}, \mathrm{Mg}^{+2}, \mathrm{Na}^{+}$and $\mathrm{K}^{+}$(meq L ${ }^{-1}$ ), 0.86, 0.49, 0.50 and 0.12 , respectively; soluble anions $\mathrm{CO}_{3}^{--}$, $\mathrm{HCO}_{3}, \mathrm{Cl}^{-}$and $\mathrm{So}_{4}^{--}\left(\mathrm{meq} \mathrm{L}{ }^{-1}\right), 0.0,1.0,0.66$ and 0.31 , respectively; available $\mathrm{N}\left(\mathrm{Kg} \mathrm{mg}^{-1}\right), 6.44$; available $\mathrm{P}\left(\mathrm{Kg} \mathrm{mg}^{-1}\right), 5.80$; available $\mathrm{K}(\mathrm{Kg} \mathrm{mg}$ $\left.{ }^{1}\right), 351.1$. Also, total count of bacteria, $150 \times 10^{6}$ $\mathrm{CFU}$; total count of fungi, $75 \times 10^{4} \mathrm{CFU}$ and total count of actinomycetes, $45 \times 10^{5} \mathrm{CFU}$. (Allen, 1959). The experiment was carried out as $2 \times 12$ x 7 complete randomized block designed, i.e. 2 treatments (infested and non-infested soil) and 12 inoculation treatments with 7 replicates for each treatment. Peatmoss- based inoculum contained $R$. solani $\left(1 \mathrm{X} 10^{6}\right.$ spores $\left.\mathrm{ml}^{-1}\right)$ was mixed with 
the soil of the infested treatments $\left(6 \mathrm{Kg}\right.$ soil pot $\left.^{-1}\right)$ at the rate of $5 \mathrm{~g} \mathrm{Kg}^{-1}$ of soil. This soil was put in $30 \mathrm{~cm}$ diameter and $35 \mathrm{~cm}$ depth pots. The soil moisture maintained at $60 \%$ of water holding capacity. Soybean seeds were surface sterilized, then ten seeds were sown in each pot. At the same time, all plants were inoculated with the biofertilizer inoculants $1 \mathrm{X} 10^{9} \mathrm{CFU}$ at the rate of $10 \mathrm{ml} \mathrm{pot}^{-1}$ (Attia et al. 2011). The mineral fertilizers comprised urea $(46.5 \% \mathrm{~N})$, calcium super-phosphate $\left(15 \% \quad \mathrm{P}_{2} \mathrm{O}_{5}\right)$, and potassium sulphate $\left(48 \% \mathrm{~K}_{2} \mathrm{O}\right)$. The experiment involved the following 12 treatments with and without $R$. solani infestation as shown in Table 1.

\section{Growth parameters}

Sixty day old, plants were taken to determine shoot and root lengths ( $\mathrm{cm}$ plant $\left.{ }^{-1}\right)$, shoot and root dry weight (g plant $\left.{ }^{-1}\right)$, number of nodules and dry weight of nodules (mg plant $\left.{ }^{-1}\right)$, chlorophyll content, nitrogen, phosphorus and potassium (\%) of shoot and root.

Seeds yield were recorded at harvesting time as $\left(\mathrm{g}\right.$ plant $\left.{ }^{-1}\right)$.

\section{Growth inhibition}

Growth inhibition was measured on a scale from 0 to 3 (Korsten et al. 1995), where $0=$ no growth inhibition, $1=1$ to $25 \%$ growth inhibition,
$2=26$ to $50 \%$ growth inhibition and $3=51$ to $75 \%$ growth inhibition

Disease assessment

According to Arafa (1985), pathogenicity was tested as follows:

a- Percentage of pre-emergence damping off was determined after 15 days:

Pre-emergence $(\%)=$ No. of ungerminated seeds $/$ No. of sown seeds $\times 100$

b- Percentage of post- emergence damping off was determined after 30 days:

Post- emergence $(\%)=$ No. of died seedlings $/$ No. of survival plants $\times 100$

c- Percentage of diseased plants was determined after 60 days:

Diseased plants $(\%)=$ No. of infested plants with root-rot / No. of survival plants $\times 100$

\section{Statistical analysis}

All obtained data were statistically analyzed according to the technique of analysis of variance (ANOVA) for the randomized complete block designed to experiment using the L.S.D. method according to (Steel and Torrie, 1980).

\section{TABLE 1. Treatments used for pot experiment.}

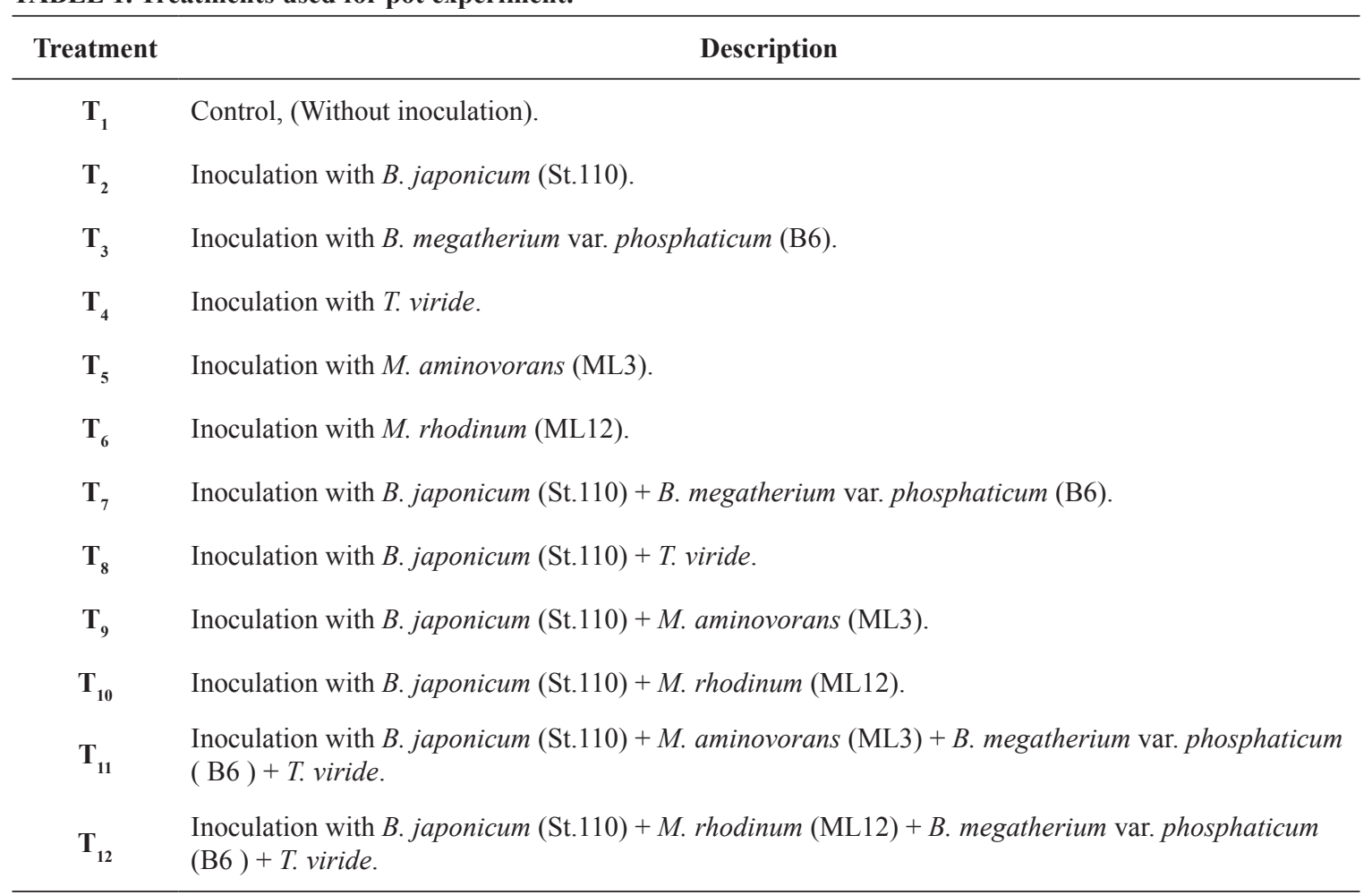




\section{Results}

\subsection{Laboratory experiment (in vitro):}

After 5 days of incubation at $30^{\circ} \mathrm{C}$, all microorganisms under study showed differences in their ability to inhibit mycelial growth of $R$. solani (Table 2 and Figure 1). The maximum mycelial growth inhibition percentage was recorded in T. viride followed by $M$. rhodinum ( 74.50 and $72.61 \%$ ), while the minimum mycelial growth inhibition percentage was recorded for B. megaterium $(54.33 \%)$ on PDA medium respectively. But on YEMA medium the results showed that $B$. japonicum attained $61.41 \%$. Also, T. viride and $B$. megaterium gave $72.60 \%$ and $59.90 \%$ on NA medium. On the other hand, $M$. rhodinum and $M$. aminovorans were recorded $69.30 \%$ and $66.80 \%$ on AMS medium.

\section{Pot experiment (in vivo)}

Data of Table 3 and Figure 2 showed that all treatments decreased damping off $\%$ and increased healthy plants compared with the control treatment (T1). In the infested soil, the inoculation with the different bio-inoculants revealed different decreases in damping-off plants. The lowest pre-emergence dampingoff plants (15 days old) were recorded for the treatments $\mathrm{T}_{10}, \mathrm{~T}_{11}$ and $\mathrm{T}_{12}(10 \%)$ compared to un-inoculated control (50\%). Under non-infested soil with $R$. solani, the highest percentage of preemergence damping off was $30 \%$ in $\mathrm{T}_{1}$ treatment compared with the lowest percentage $(0.00 \%)$ for $\mathrm{T}_{10}, \mathrm{~T}_{11}$ and $\mathrm{T}_{12}$ treatments. Also, the postemergence percentages damping-off plants (30 days old) showed notable decreases due to

TABLE 2. Percent of mycelial growth inhibition rates of $R$. solani on different media by microorganisms under study at 5 days after inoculation.

\begin{tabular}{lcccccccc}
\hline \multicolumn{1}{c}{ Organism } & \multicolumn{7}{c}{ Mycelial growth inhibition (\%) } \\
\hline \multicolumn{1}{c}{ Media } & PDA & GI & AMS & GI & YEMA & GI & NA & GI \\
B. japonicum & 56.16 & 3 & - & - & 61.41 & 3 & - & - \\
B. megaterium & 54.33 & 3 & - & - & - & - & 59.90 & 3 \\
T. viride & 74.50 & 3 & - & - & - & - & 72.60 & 3 \\
M. aminovorans & 71.20 & 3 & 66.80 & 3 & - & - & - & - \\
M. rhodinum & 72.61 & 3 & 69.30 & 3 & - & - & - & - \\
\hline
\end{tabular}
agar, GI: Growth inhibition.

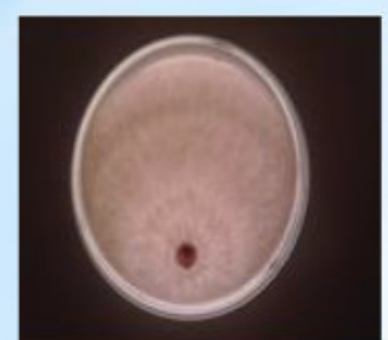

R. solani'(control)

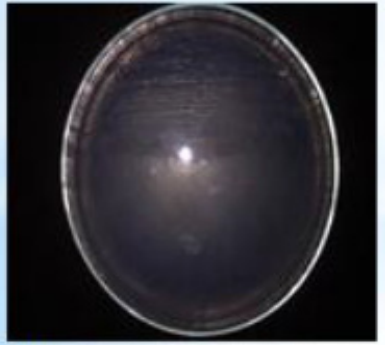

R. solani and B. japonicum

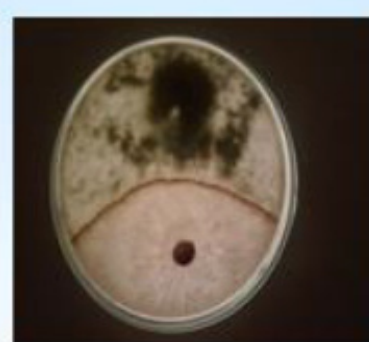

R. solani and $I$ viride

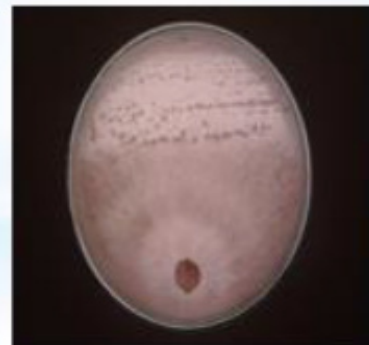

R. solani and $M$. aminovorans

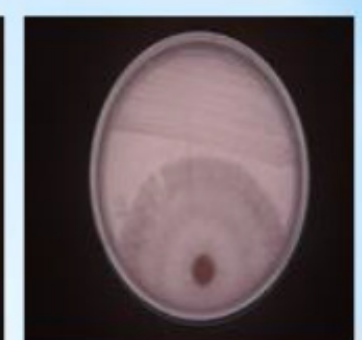

R. solani and B. megaterium

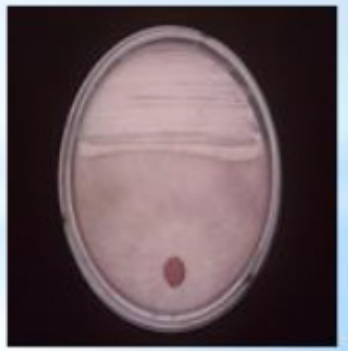

$\boldsymbol{R}$. solani and $M$. rhodinum

Fig. 1. In vitro inhibition of $R$. solani by studied microorganisms.

Env. Biodiv. Soil Security Vol.2 (2018) 
TABLE 3. Damping-off \% and diseased plants \% of soybean plants under different bio-inoculants affected by infested and non-infested with $R$. solani.

\begin{tabular}{|c|c|c|c|c|c|c|}
\hline \multirow{2}{*}{ Treatment } & \multicolumn{2}{|c|}{ Pre-emergence $(\%)$} & \multicolumn{2}{|c|}{ Post-emergence (\%) } & \multicolumn{2}{|c|}{ Diseased plants (\%) } \\
\hline & Non. & In. & Non. & In. & Non. & In. \\
\hline $\mathrm{T}_{1}$ & $30.00^{c}$ & $50.00^{\mathrm{d}}$ & $16.66^{\mathrm{c}}$ & $66.66^{\mathrm{c}}$ & $33.33^{\mathrm{b}}$ & $100^{c}$ \\
\hline $\mathbf{T}_{2}$ & $10.00^{b}$ & $30.00^{c}$ & $12.50^{b}$ & $33.33^{b}$ & $0.00^{a}$ & $33.33^{b}$ \\
\hline $\mathbf{T}_{3}$ & $10.00^{\mathrm{b}}$ & $30.00^{c}$ & $12.50^{\mathrm{b}}$ & $33.33^{b}$ & $0.00^{a}$ & $33.33^{b}$ \\
\hline $\mathbf{T}_{4}$ & $10.00^{\mathrm{b}}$ & $30.00^{\mathrm{c}}$ & $12.50^{\mathrm{b}}$ & $33.33^{b}$ & $0.00^{\mathrm{a}}$ & $33.33^{\mathrm{b}}$ \\
\hline $\mathbf{T}_{5}$ & $10.00^{\mathrm{b}}$ & $30.00^{c}$ & $12.50^{\mathrm{b}}$ & $33.33^{b}$ & $0.00^{\mathrm{a}}$ & $33.33^{b}$ \\
\hline $\mathbf{T}_{6}$ & $10.00^{b}$ & $30.00^{\mathrm{c}}$ & $12.50^{\mathrm{b}}$ & $33.33^{b}$ & $0.00^{\mathrm{a}}$ & $33.33^{b}$ \\
\hline $\mathbf{T}_{7}$ & $10.00^{b}$ & $30.00^{c}$ & $12.50^{\mathrm{b}}$ & $33.33^{b}$ & $0.00^{a}$ & $0.00^{a}$ \\
\hline$T_{8}$ & $10.00^{\mathrm{b}}$ & $30.00^{c}$ & $12.50^{\mathrm{b}}$ & $33.33^{b}$ & $0.00^{\mathrm{a}}$ & $0.00^{\mathrm{a}}$ \\
\hline$T_{9}$ & $10.00^{\mathrm{b}}$ & $20.00^{b}$ & $12.50^{\mathrm{b}}$ & $0.00^{\mathrm{a}}$ & $0.00^{\mathrm{a}}$ & $0.00^{\mathrm{a}}$ \\
\hline$T_{10}$ & $0.00^{\mathrm{a}}$ & $10.00^{\mathrm{a}}$ & $11.11^{\mathrm{a}}$ & $0.00^{\mathrm{a}}$ & $0.00^{\mathrm{a}}$ & $0.00^{\mathrm{a}}$ \\
\hline$T_{11}$ & $0.00^{\mathrm{a}}$ & $10.00^{\mathrm{a}}$ & $11.11^{\mathrm{a}}$ & $0.00^{\mathrm{a}}$ & $0.00^{a}$ & $0.00^{\mathrm{a}}$ \\
\hline$T_{12}$ & $0.00^{\mathrm{a}}$ & $10.00^{\mathrm{a}}$ & $11.11^{\mathrm{a}}$ & $0.00^{\mathrm{a}}$ & $0.00^{\mathrm{a}}$ & $0.00^{\mathrm{a}}$ \\
\hline LSD (5\%) & & & & & & \\
\hline
\end{tabular}

T1: Control, T2: inoculation with B. japonicum T3: inoculation with $B$. megaterium T4 : inoculation with T. viride T5: inoculation with $M$. aminovorans T6: inoculation with $M$. rhodinum $\mathrm{T} 7$ : inoculation with $B$. japonicum $+B$. megaterium T8: inoculation with $B$. japonicum $+T$. viride T9: inoculation with $B$. japonicum $+M$. aminovorans $\mathrm{T} 10$ : inoculation with B. japonicum $+M$. rhodinum T11: inoculation with B. japonicum + M. aminovorans $+B$. megaterium + T. viride $\mathrm{T} 12$ : inoculation with B. japonicum + M. rhodinum + B. megaterium + T. viride. Non: Non-infested, In: Infested.

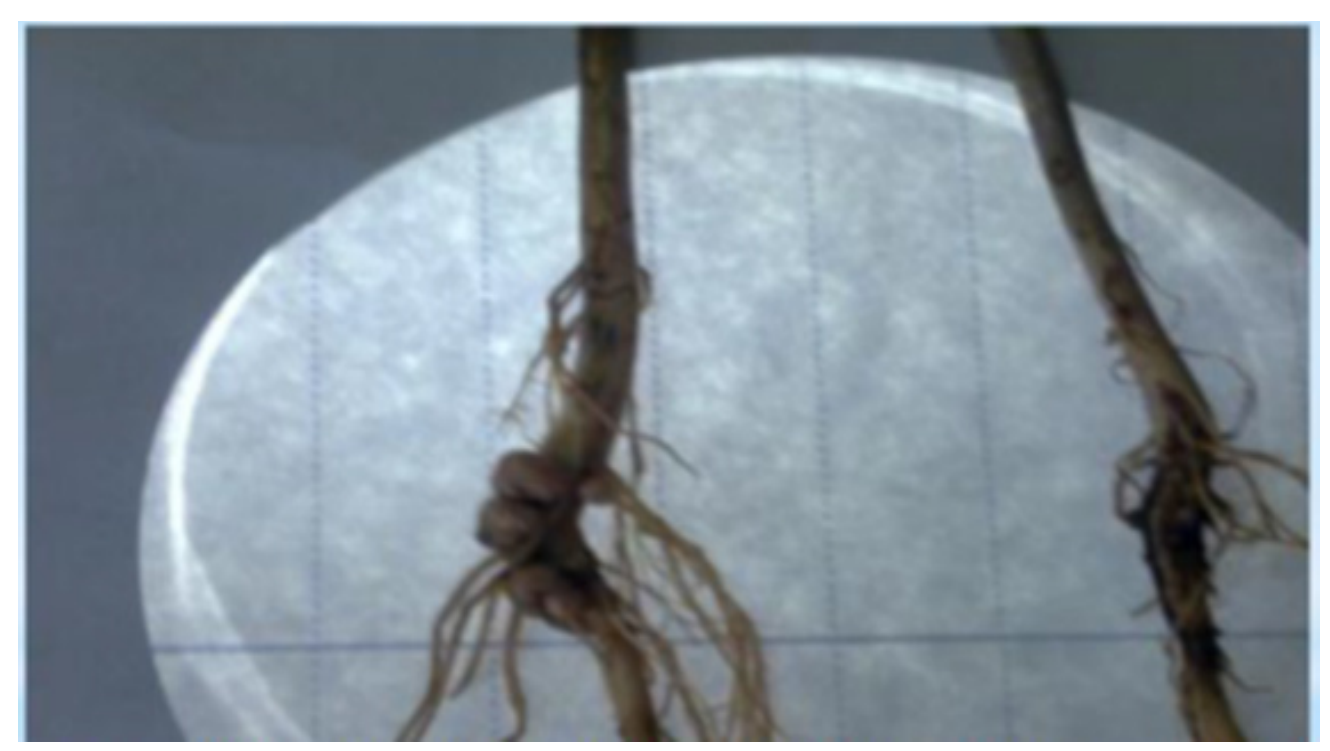

Fig. 2. Infested (Right) and Non-infested (Left) of soybean plant with $R$. solani (In vivo). 
the different studied bio- inoculants, the most effective treatments were $\mathrm{T}_{10}, \mathrm{~T}_{11}$ and $\mathrm{T}_{12}$ which highly decreased it by percentages of $11.11,11.11$ and $11.11 \%$ respectively for non-infested soil and completely prevent post-emergence $\%$ for the infested soil. Concerning the percentage of diseased plants (60 days old), the most effective treatments $(0.00 \%)$ were those between $T_{7}$ to $T_{12}$ compared to the control $\left(\mathrm{T}_{1}\right)$ under infested and non-infested soils (100 and $33.33 \%$ ).

\section{Vegetative growth and Yield}

The inoculation with $T$. viride and/or other studied inoculants revealed notable increases over un-inoculated control. The differences mostly were significant. $\mathrm{T}_{12}$ treatment gave the highest shoot and root dry weights under circumstances of non-infestation or infestation. It recorded 8.50 and $0.68 \mathrm{~g} \mathrm{plant}^{-1}$ for non-infested and 7.86 and $0.63 \mathrm{~g} \mathrm{plant}^{-1}$ for infested soil (Table 4).

TABLE 4. Shoot, root dry weight $\left(\mathrm{g} \mathrm{plant}^{-1}\right)$, number of nodules, dry weight of nodules $\left(\mathrm{mg} \mathrm{plant}^{-1}\right)$ chlorophyll content and seed yield $\left(\mathrm{g} \mathrm{plant}^{-1}\right)$ of soybean plants infested and non-infested with $R$. solani under different bio-inoculants.

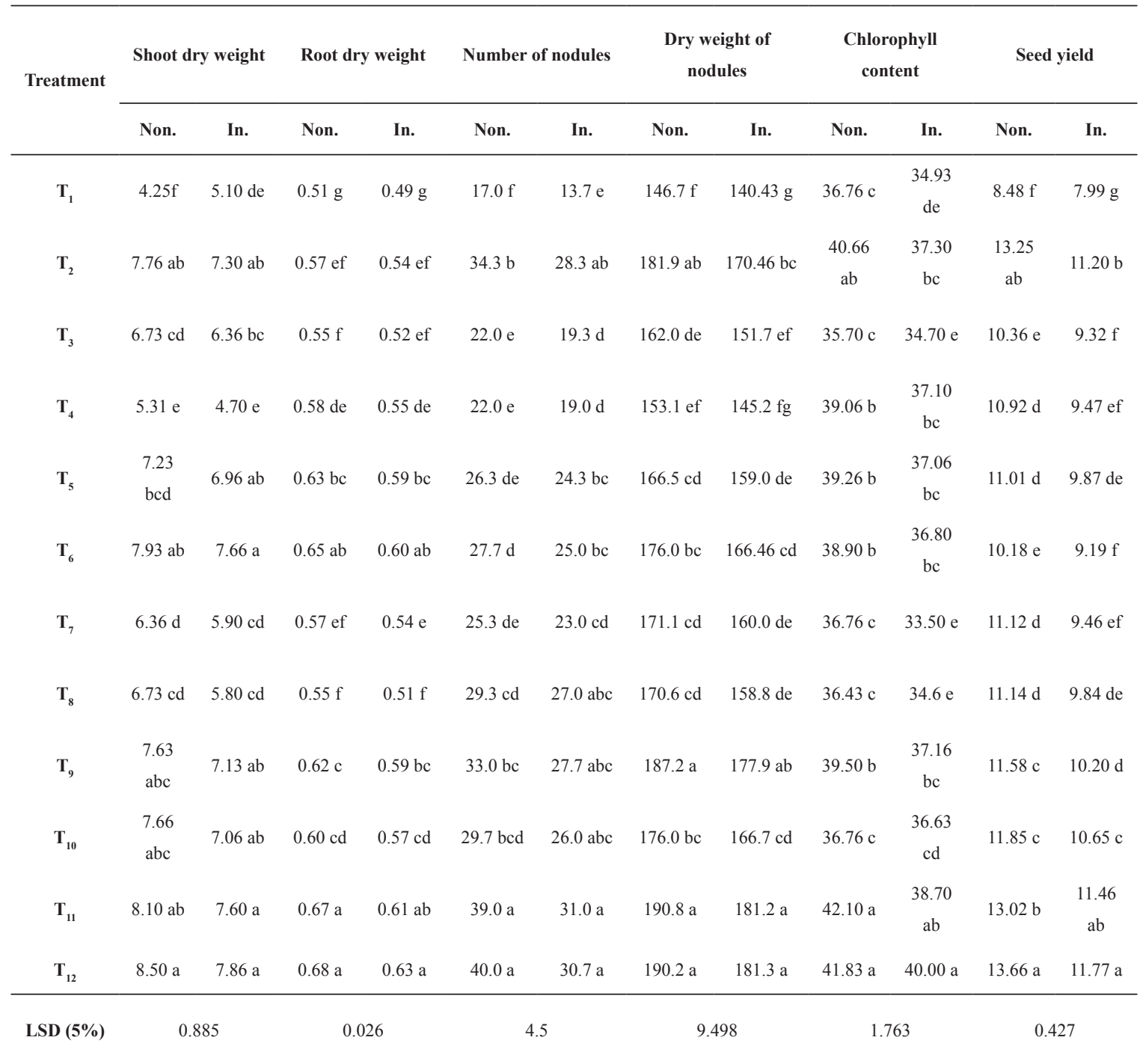

T1: Control, T2: inoculation with B. japonicum, T3: inoculation with B. megaterium, T4 : inoculation with $T$. viride, T5: inoculation with $M$. aminovorans, T6: inoculation with $M$. rhodinum, T7: inoculation with $B$. japonicum $+B$. megaterium, T8: inoculation with $B$. japonicum $+T$. viride, T9: inoculation with $B$. japonicum $+M$. aminovorans, T10: inoculation with $B$. japonicum $+M$. rhodinum, T11: inoculation with $B$. japonicum $+M$. aminovorans $+B$. megaterium $+T$. viride, T12: inoculation with $B$. japonicum $+M$. rhodinum + B. megaterium + T. viride. Non.: Non-infested, In.: Infested.

Env. Biodiv. Soil Security Vol.2 (2018) 
They gave significant increases over control $\left(\mathrm{T}_{1}\right)$ reached 39.0 and 40.0 for non-infested soil and 31.0 and 30.7 nodules plant ${ }^{-1}$ for infested one compared to 17.0 and 13.7 nodules plant ${ }^{-1}$ for $\mathrm{T}_{1}$ treatment. It is noticed that inoculant type containing rhizobia showed higher nodules number over other treatments having no rhizobia. The dry weight of nodules of soybean plants showed similar trend as number of nodules. The treatments $\mathrm{T}_{11}$ and $\mathrm{T}_{12}$ were the superior in this context under both infested or non-infested circumstances and the differences than un-inoculated control were highly significant. The increase in number and dry weight of nodules in case of inoculated treatments may be attributed to the effective specific rhizobia contained in the applied inoculum. While, the increase in number and dry weight of nodules resulted from the other inoculants which did not contain rhizobia may be due to the positive effect of the other microbial inoculants like $B$. megaterium and methylotrophic bacteria on the native rhizobia present in soil. Among the single microbe inoculants, the inoculant of rhizobia $\left(\mathrm{T}_{2}\right)$ attained the highest chlorophyll value (40.66 and 37.30) under non-infested and infested soils. The chemical fertilized control treatment have the lowest value (36.76 and 34.93), but the treatments $\mathrm{T}_{11}$ and $\mathrm{T}_{12}$ which were composite inoculants were the best in this context. They obtained 42.10 and 41.83 for non-infested soil and 38.70 and 40.0 for infested soil (Table 4). Seeds yield of soybean plants responded positively due to the application of the different inoculants (Table 4). The yields in case of non-infested soil were higher than those of the infested one in respect to all studied inoculants and control. The composite inoculants of $\mathrm{T}_{11}$ and $\mathrm{T}_{12}$ attained the highest seeds yield in both non-infested and infested soils over control $\left(T_{1}\right)$ followed by the rhizobia inoculum $\left(T_{2}\right) . T_{11}$ and $\mathrm{T}_{12}$ recorded 13.02 and 11.77 for infested one, the $\mathrm{T}_{1}$ treatment gave 8.48 and 7.99 respectively.

\section{Mineral uptake}

Nitrogen percentages of shoot and root system of soybean plants increased as a result of inoculation with the studied inoculants (Table 5). The increase in percentages of shoot $\mathrm{N}$ over control treatment ranged from $2.77 \%$ to $2.50 \%$, due to $\mathrm{T}_{12}$, and $\mathrm{T}_{7}$ treatments, respectively, in non-infested plants and from $2.65 \%$ to $2.41 \%$, for $\mathrm{T}_{12}$, and $\mathrm{T}_{3}$ treatments, respectively, in infested plants. The data of N\% of root approximately exhibited similar trend, whereas the increase ranged from $1.61 \%$ for $\mathrm{T}_{12}$ to $1.42 \%$ for $\mathrm{T}_{7}$ in respect of the non-infested plants, while in the infested plants, the percentages ranged from $1.43 \%$ for $\mathrm{T}_{12}$ to $1.34 \%$ for $\mathrm{T}_{6}$. It is noted that, nitrogen percentages of shoots showed a consistent increase over those of roots. The differences over $\mathrm{T}_{1}$ control were significant.

As shown in Table 5, the influence of the studied inoculants on the shoot - $\mathrm{p} \%$ have a similar trend under non-infestation and infestation. Whereas, $\mathrm{T}_{12}$ treatment gave $0.47 \%$ and $0.36 \%$ followed by $\mathrm{T}_{11}(0.43 \%$ and $0.35 \%)$ then $\mathrm{T}_{7}(0.42 \%$ and $0.35 \%)$ respectively, in relation to control $\left(\mathrm{T}_{1}\right)$ which exhibited $0.28 \%$ and $0.23 \%$. The increases over control were highly significant. On the other hand, the results of root $-\mathrm{p} \%$ have a similar trend as shoot $-\mathrm{p} \%$ except for the high values of $p-$ percentages of shoot compared to root $-p \%$. Whereas, the $\mathrm{T}_{12}$ treatment attained $\mathrm{p} \%$ evaluated $0.39 \%$ and $0.30 \%$ followed by $\mathrm{T}_{11}$ which gave $0.36 \%$ and $0.29 \%$ then $\mathrm{T}_{7}(0.35 \%$ and $0.29 \%)$. The differences over control which exhibited $0.21 \%$ and $0.18 \%$ were highly significant.

Data presented in Table 5 showed that inoculation with the different inoculants variably increases potassium percentages of shoots and roots of soybean plants. In case of non-infestation with $R$. solani in shoots, the increases ranged from $0.18 \%$ caused by $\mathrm{T}_{12}$ treatment to $0.14 \%$ for treatments of $\mathrm{T}_{4}$ and $\mathrm{T}_{5}$ compared to $0.13 \%$ for control $\left(\mathrm{T}_{1}\right)$. Also, the infested plants responded positively due to inoculation with the different inoculants ranged from $0.16 \%$ for $\mathrm{T}_{12}$ as compared to $0.11 \%$ for control $\left(\mathrm{T}_{1}\right)$. The differences than control were highly significant. The concentrations of potassium in roots have the same trend of shoots.

\section{Discussion}

Since many years, pesticides have been used to control soil borne disease and pest of economically important crops. Also, the use of chemicals has been reduced which due to pollution of environment, especially water and food. The results indicated that several individual strains and several mixtures of PGPR may provide significant disease suppression against specific tested pathogens of soybean.

Herein, the effect of some microorganisms plant growth promoting (Bradyrhizobium japonicum, Bacillus megaterium var. phosphaticum, Methylobacterium aminovorans, Methylobacterium rhodinum, and Trichoderma viride) were evaluated in vitro and in vivo against $R$. solani infected soybean plants which can promote plant growth directly or indirectly. Indirect effects are related to production of Env. Biodiv. Soil Security Vol.2 (2018) 
TABLE 5. Nitrogen, phosphorus and potassium (\%) in shoot and root of soybean plants infested and non-infested with $R$. solani under different bio-inoculants.

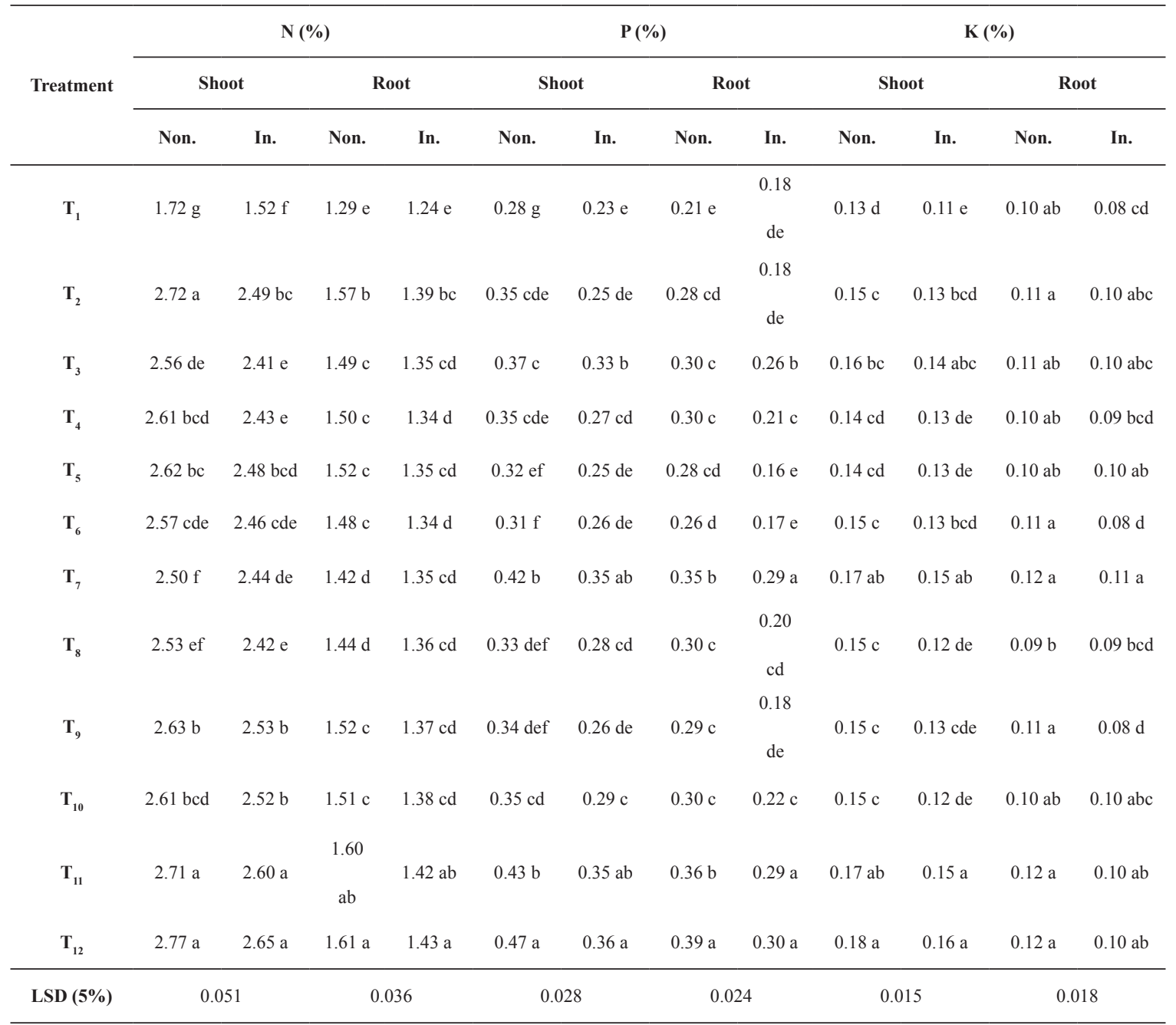

T1: Control, T2: inoculation with B. japonicum, T3: inoculation with $B$. megaterium, T4 : inoculation with $T$. viride, T5: inoculation with $M$. aminovorans, T6: inoculation with $M$. rhodinum, T7: inoculation with $B$. japonicum $+B$. megaterium, T8: inoculation with B. japonicum + T. viride, T9: inoculation with B. japonicum + M. aminovorans, T10: inoculation with $B$. japonicum $+M$. rhodinum, T11: inoculation with $B$. japonicum $+M$. aminovorans $+B$. megaterium $+T$. viride, T12: inoculation with $B$. japonicum + M. rhodinum $+B$. megaterium + T. viride. Non.: Non-infested, In.: Infested.

metabolites, such as antibiotics, that decrease the growth of phytopathogens and other deleterious microorganisms. Direct effects are depended on production of plant growth regulators (Chin-AWoeng et al. 2001, Raaijmkers et al. 2002).

The obtained results confirmed that the biocontrol capability of some species within the genus Trichoderma against a wide range of important plant pathogens (McLean et al. 2004). Strains of the Trichoderma species are known to produce a number of antibiotics, such as trichodermin, trichodermol $\mathrm{A}$ and harzianolide (Claydon et al. 1991), which are responsible for most of the inhibition of fungal phytopathogens.
Also, the interaction between the antagonists as well as the pathogen and occurrence of inhibition zone on agar media could be commonly considered as a result of the production of the antibiotics and competition for nutrients and space as observed by (Ashour and Afify, 1999, El-Katatny et al. 2001). Also, Schirmbock et al. (1994), reported that antibiotics and hydrolytic enzymes are not only produced together but act synergistically in mycoparasitic antagonism. As well as Bacillus megaterium is considered a biocontrol agent which gave the same effect of inhibition zone on agar madia through production of antibiotics. Bacillus megaterium is a potential bacterial biocontrol agent against Rhizoctonia

Env. Biodiv. Soil Security Vol.2 (2018) 
solani that are shown by (Zheng and Sinclair, 2000). In addition to, several other workers have noticed the beneficial effects of Bradyrhizobium on plant growth and reduction of diseases incidence (Hussain and Ghaffar, 1990). Since, the rhizosphere provides front line defense for roots against attack by pathogens, the Bradyrhizobium present in the rhizosphere are ideal for use as biocontrol agents. Reduction of fungal growth in vitro by some Bradyrhizobium and formation of inhibition zones were presumably due to the metabolites released by the bacteria into the culture medium. Also, (Khan et al. 1997) reported that Bradyrhizobium produces toxic metabolites which have inhibitory effect on soil-borne plant pathogens.

Genus Methylobacterium is well-known growth regulator producers and also having in vitro biocontrol ability of against the phytopathogen Rhizoctonia solani that showed by (Poorniammal et al. 2009). Effect of plant growth promoting on root rot and wilt disease complex of soybean plant under greenhouse conditions was also studied. Data showed that soil treated with $N F B$ plus Bacillus cereus (BC) or Bacillus megaterium (BM) or Pseudomonas fluorescens (PF) significantly reduced diseased plants comparing with the control (Attia et al. 2011). Systemic acquired resistance (SAR) and induced systemic resistance (ISR) are two forms of induced resistance wherein plant defenses are preconditioned by prior infection or treatment that results in resistance against subsequent challenge by a pathogen or parasite (Choudhary et al. 2007). The widely recognized mechanism of biocontrol mediated by PGPR is competition for an ecological niche/substrate, production of inhibitory allelochemicals, and induction of systemic resistance (ISR) in host plants to a broad spectrum of pathogens (Hass et al. 2002).

Application of B. japonicum isolates significantly reduced the wilting index and increased plant growth of chickpeas. These Bradyrhizobium also increased nitrogen content, dry weight of nodules and dry weight of roots and shoots under infested soil with damping-off fungi (Hussain and Ghaffar, 1990). In addition, the results showed that inoculation alone or combined with Bradyrhizobium, B megaterium and T. viride gave reduced the damping-off and infested soybean plants as compared with untreated control and also increased dry weight of nodules and dry weight of roots and shoots (Mazen et al.
2008, Attia et al. 2001).

It is noticed that inoculant type which contains rhizobia showed higher nodules number over other treatments had no rhizobia. The dry weight of nodules of soybean plants showed similar trend as number of nodules. The treatments $T_{11}$ and $T_{12}$ were the superior in this context under both infested or non-infested circumstances and the differences than un-inoculated control were highly significant. The increase in number and dry weight of nodules in case of inoculated treatments may be attributed to the effective specific rhizobia contained in the applied inoculum. While, the increase of number and dry weight of nodules resulted from the other inoculants which did not contain rhizobia may be resulted from the positive effect of the other microbial inoculants like $B$. megaterium and methylotrophic bacteria on the native rhizobia present in soil.

Many researchers were worked on soybean plant and observed that inoculation of soybean with Bradyrhizobium has increased the nodulation parameters, nitrogen fixation and yield of crop (Radha 2007, Meenakshi et al. 2009). The results showed complete similarity to observations of (Madhaiyan et al. 2004) where, they observed that the Methylobacterium inoculation was found to increase the photosynthetic activity by enhancing the number of stomata, chlorophyll concentration and malic acid content of crops.

The increase in $\mathrm{N}$ uptake due to combined inoculation of two or more organisms has been documented by several workers (Deranada 2000). Similarly, (Radha et al. 2009) which worked on soybean plant and observed that inoculation of soybean with Bradyrhizobium and PPFMs has been reported to increase the uptake nitrogen $\%$ in shoot and root, nodulation and yield of crop as compared to control. Several biocontrol agents alone or in combination with three phosphatesolubilizing strains of Bacillus megaterium have been employed to control the root-rot disease complex of chickpea caused by Meloidogyne incognita and Macrophomina phaseolina and increase in P uptake (Siddiqui and Akhtar 2007). The concentrations of potassium in roots have the same trend of shoots. The increase in K uptake due to combined inoculation of two or more organisms has been documented by (Radha et al. 2009) which worked on soybean plant and observed that inoculation of soybean with Bradyrhizobium and PPFMs has been reported to increase the uptake of $\mathrm{K} \%$ in shoot and root, nodulation and yield of 
crop as compared to control.

\section{Acknowledgments}

We are extremely grateful to all staff members and colleagues in The Bacterial Research Laboratory, Sakha Agricultural Research Station, Agriculture Research Center, Egypt and Institute of Sciences of Food Production (ISPA-CNR), Bari, Italy.

\section{References}

Allen, O. N. (1959) Experiments in Soil Bacteriology. Burgess pub. Co., Ninn, Minnesota.

Arora, N. K.. Kang, S. C. and Maheshwari, D. K (2001) Isolation of siderophore producing strains of Rhizobium meliloti and their biocontrol potential against Macrophomina phaseolina that causes charcoal rot of groundnut. Current Sci., 81, 679-677.

Arafa MK (1985) Studies on Fusarium wilt of cumin. M.Sc. Thesis, Assiut University, Egypt.

Ashour, A. Z. A. and Afify, Aida, H. (1999) Biological control of cotton seedling disease by rhizobacteria. $2^{\text {nd }}$, Int. Con. Pest Control, Mansoura, Egypt. 9, 357-370.

Ashour, A. Z. A. and Afify, Aida, H. (2000) Biocontrol of flax seedling blight with mixtures of Pseudomonas spp. Pakistan J. Biological Sci. 3(3), 368-371.

Atlas, R. M. (1997) Handbook of Microbiological Media CRC Pres. Second Edition. New York. p. 1026.

Attia, M.; Nemat; Awad, M.; Turky, A. S. and Hamed, H. A. (2011) Induction of defense responses in soybean plants against Macrophomina phaseolina by some strains of plant growth promoting rhizobacteria J. Appl. Sci. Res. 7, 1507-1517.

Chin-A-Woeng, T.F.; J.E. Thomas; B.J. Lugtenberg and Bloemberg G.V. (2001) Introduction of the PhzH gene of Pseudomonas chlororaphis PCL1391 extends the range of biocontrol of phenazinel carboxylic acid producing Pseudomonas. Mol. Plant Microb. Interact., 14, 1006-1015.

Choudhary, D.; Prakash, A. and Johri, B. (2007) Induced systemic resistance (ISR) in plants: mechanism of action. Indian J. Microbiol., 47, 289-297.

Claydon, N.; Hanson, J.; Truneh, A. and A. Avent. (1991) Harzianolide, a butenolide metabolite from cultures of Trichoderma harzianum. Phytochem. 30, 3802-3803.

Devanada, B. J. (2000) Role of plant growth promoting rhizobacteria on growth and yield of pigeonpea (Cajanus cajan L.) cultivars. M.Sc. (Agric.) Thesis, Univ. Agric. Sci., Dharwad, India.

Elad, Y., Viela, Y. and Chet, L. (1986) Biological control of Rhizoctonia solani damping-off with wheat bran culture of Trichoderma harzianum Phytapathology

Env. Biodiv. Soil Security Vol.2 (2018)
69, 64-68.

El-Katatny, M., Gudelj, M., Robra, K.; Elnaghy, M. and Gubitz, G. (2001) Characterization of a chitinase and an endo-b-1,3- glucanase from Trichoderma harzianum Rifai T24 involved in control of the phytopathogen Sclerotium rolfsii. Appl. Microbiol. Biotech., 56,137-143.

Glick, B. R. (1995) The enhancement of plant growth by free living bacteria. Can. J. Microbiol., 41, 109-117.

Haas, D.; Keel, C. and Reimmann, C. (2002) Signal transduction in plant beneficial rhizobacteria with biocontrol properties. Antonie Leeuwenhoek, 81, 385-395.

Huang, X.F., Zhou, D., Guo, J., Manter, D.K., Reardon, K.F. and Vivanco, J.M. (2015) Bacillus spp. from rainforest soil promote plant growth under limited nitrogen conditions. J. Appl. Microbiol., 118, 672-684. doi:10.1111/jam.12720.

Hussain S. and Ghaffar, A. (1990) Biological control of Macrophomina phaseolina charcoal rot of sunflower and mung bean. J. Phytopatho., 130, 157-160.

Kaul, A. K. and Das, M. L. (1986) Oilseeds in Bangladesh. Bangladesh Canada Agriculture Sector Team. Ministry of Agriculture, Govt. of the People's Republic of Bangladesh, Dhaka. p.324

Keshavarz-Tohid, V., Taheri, P., Muller, D., PrigentCombaret, C., Vacheron, J., Taghavi, S.M., Saeed Tarighi, S. and Moëenne-Loccoz, Y. (2017) Phylogenetic diversity and antagonistic traits of root and rhizosphere pseudomonads of bean from Iran for controlling Rhizoctonia solani. Research in Microbiology, 168, 760-772

Khan, M., Zaidi, A. and Amil, M. (1997) Associative effect of Bradyrhizobium sp. (vigna) and phosphate solubilizing bacteria on mungbean [Vigna radiata (L.) Wilczek]. Biojounal, 9, 101-106.

Korsten, L., De Jager, E. S., De Villiers, E. E., Lourens A. and Wehner, F.C. (1995) Evaluation of bacterial epiphytes isolated from avocado leaf and fruit surfaces for biocontrol of avocado postharvest diseases. Plant Disease 79, 1149-1156.

Lu, X., Zhou, D., Chen, X., Zhang, J., Huang, H. and Wei, L. (2017) Isolation and characterization of Bacillus altitudinis JSCX-1 as a new potential biocontrol agent against Phytophthora sojae in soybean [Glycine max (L.) Merr.]. Plant Soil; 416 , 53-66. DOI 10.1007/s11104-017-3195-z

Madhaiyan, M., Poonguzhali, S., Senthilkumar, M., Seshadri, S., Chung, H., Yang, J., Sundaram, S. P. and Tongmin, S.A. (2004) Growth promotion and induction of systemic resistance in rice cultivar 
Co-47 (Oryza sativa L.) by Methylobacterium spp. Botanical Bulletin Academy Sin., 45, 315-325.

Mazen, M. M., El-Batanony. N. H., Abd El-Monium, M. M. and Massoud, O. N. (2008) Cultural Filtrate of Rhizobium spp. and Arbuscular Mycorrhiza are Potential Biological Control Agents Against Root Rot Fungal Diseases of Faba Bean. G. J. Biote. \& Bioch. 3, 32-41.

McLean, K., Dodd, S., Sleight, B., Hill, R. and Stewart, A. (2004) Comparison of the behavior of a transformed hygromycin resistant strain of Trichoderma atoviride with the wild-type strain. New Zealand Plant Protection, 57, 72-76.

Meenakshi, B. C. and Savalgi, V. P. (2009) Effect of coinoculation of Methylobacterium and B. japonicum on plant growth dry matter content and enzyme activities in soybean. Karnataka J. Agric. Sci., 22, 344 -348

Okon, Y., Albrecht, S. L. and Burris, R. H. (1977) Methods for growing Spirillum lipoferum and for counting it in pure culture and in association with plants. Appl. Environ. Microbiol., 33, 83-85.

Omar, S. A. (1986) Pathological studies on root-rot disease of faba bean (vicia faba L.) $11^{\text {th }}$ con. Sci., Soc. and Research Cairo, Egypt, pp: 33-48.

Patten, C. L. and Glick, B. R. (2002) Role of Pseudomonase putida indole acetic acid in development of the host plant root system. Appl. Environ. Microbiol., 68, 3795-3801.

Poorniammal, R., S.P. Sundaram and Kumutha K. (2009) Induced systemic resistance by Methylobacterium extorquens against Rhizoctonia solani in cotton. Inter. J. Plant Prot. 2(2), 199-204.

Raaijmakers, J.M., M. Valmi and de Souza, J.T. (2002) Antibiotic production by bacterial biocontrol agents. Antonie van leeuwenkoek, 18, 537-547.

Radha, T. K. (2007) Studies on methylotrophes and their beneficial effects on soybean (Glycine max (L.) Merrill). M.SC. Dep. Agri. Micro. Coll. Agric. Uni. Agric. Sci. Dharwad - 580 005, India.

Radha, T. K.; Savalgi, V.P. and Alagawadi, A. R. (2009) Effect of methylotrophs on growth and yield of soybean (Glycine max (L.) Merrill). Karnataka J. Agric. Sci., 22, 118 - 121.

Sadeghi, A., Koobaz, P., Azimi, H., Karimi, E. and Akbari, A.R. (2017) Plant growth promotion and suppression of Phytophthora drechsleri damping-off in cucumber by cellulase-producing Streptomyces. Bio. Control., 62, 805-819. DOI 10.1007/s10526-017-9838-4

Sadfi, N., Cherif, M., Fliss, I., Boudabous, A. and Antoun, H. (2001) Evaluation of bacterial isolates from salty soils and Bacillus thuringiensis strains for the biocontrol of Fusarium dry rot of potato tubers. J. Plant Pathol., 83, 101-118.

Schirmbock, M., Lorito, M., Wang, Y., Hayes, C., ArisanAtac, I., Scala, F., Harman, G. and Kubicek, C. (1994) Parallel formation and synergism of hydrolytic enzymes and peptaibol antibiotics, molecular mechanisms involved in the antagonistic action of Trichoderma harzianum against phytopathogenic fungi. Appl. Environ. Microbiol, 60, 4364-4370.

Siddiqui, Z. and Akhtar, M. (2007) Biocontrol of chickpea root rot disease complex with phosphatesolubilizing microorganism. J. Plant Pathol., 89, 67-77.

Sikora, R. A. (1992) Management of the antagonistic potential in agricultural ecosystems for the biological control of plant parasitic nematodes. Annu. Rev. Phytopathol., 30, 145-270.

Sikora, R. A. and Reimann, S. (2004) Suppressive soils, the edge of chaos and multitrophic strategies for biocontrol of pests and diseases in soil ecosystems. In: Multitrophic Interactions In Soil, Eds., pp, 251-258.

Steel, D. and Torrie, J. H. (1980) Principles And Procedures Of Statistics. Ambiometrical Approach. 2nd ed. McGraw Hill, New York.

Vincent, J. M. (1970) A manual for the practical study of the root- nodule bacteria. IBP Handbook No. 15. Black well Sci., Pul. Oxford and Edinburgh. Pp. 54-58.

Whipps J. M. (1987) Effect of media on growth and interactions between a range of soil-borne glasshouse pathogens and antagonistic fungi. $\mathrm{New}$ Phytologist., 107, 127-142.

Wittenbury, R., Davis, S. L. and Wilkinson, J. F. (1970) Enrichment, isolation and some properties of methane utilizing bacteria. J. Gen. Microbiol., 61, 205-218.

Zheng, X. Y. and Sinclair, J. B. (2000) The effects of traits of $B$. megaterium on seed and root colonization and their correlation with the suppression of Rhizoctonia root rot of soybean. Bio. Control., 45, $223-243$.

(Received 14/3/2018; accepted 14/6/2018) 